Neuhard, J. (1966). Biochimica et Biophysica Acta, 129, 104.

Neuhard, J., and Munch-Peterson, A. (1966). Biochimica et Biophysica Acta, 114,61 .

Pritchard, R. H., and Zaritsky, A. (1970). Nature, 226, 126.

Reichard, P., Canellakis, Z. N., and Canellakis, E. S. (1961). Fournal of Biological Chemistry, 236, 2514.

Smith, L. H., Huguley, C. M., and Bain, J. A. (1966). In The Metabolic Basis of Inherited Disease, ed. J. B. Stanburg, J. B. Wyngaarden, and Basis of Inherited Disease, ed. J. B. Stanburg, J. B.
D. S. Fredrickson, p. 739, New York, McGraw-Hill.
Solter, A. W., and Handschumacher, R. E. (1969). Biochimica et Biophysica Acta, 174, 585.

Wahba, A., and Friedkin, M. (1962). Fournal of Biological Chemistry, 237, 379.

Waters, A. H., and Mollin, D. L. (1963). British fournal of Haematology, 9, 319.

Weiss, B., Jacquemin-Sablon, A., Line, T., Fareed, G., and Richardson, C. (1968). Fournal of Biological Chemistry, 243, 4543.

Wickramasinghe, S. N. (1972). British Fournal of Haematology, 22, 111.

\section{Protection of Rat Bronchial Epithelium against Tobacco Smoke}

\author{
ROSEMARY JONES, P. BOLDUC, LYNNE REID
}

British Medical fournal, 1972, 2, 142-144

\section{Summary}

Addition to tobacco of phenylmethyloxadiazole (PMO) protects rats against some of the adverse effects of exposure to cigarette smoke. Two groups of 15 rats were exposed to 25 cigarettes a day for 24 days; the group whose cigarette included PMO showed less immediate distress after exposure, a smaller tracheal goblet cell count, less thickening of the tracheal epithelium, and less cells in mitosis than those exposed to ordinary tobacco.

\section{Introduction}

Human epidemiological studies have shown that tobacco smoking causes hypersecretion of mucus which is typical of chronic bronchitis and that it induces bronchial cancer. The fundamental structural changes seem to be hypertrophy of the bronchial submucosal mucous glands and an increase in the number of goblet cells and their extension into peripheral small airways that are normally free of them. Such changes can be produced experimentally in animals by tobacco smoke and other irritants such as sulphur dioxide (Lamb and Reid, 1968, 1969; Mawdesley-Thomas, Healey, and Barry, 1971) and nitrous oxide (Freeman and Haydon, 1964). The similarity to the morphological changes in man provides a satisfactory animal model for the study of chronic bronchitis (Reid, 1970).

In animals the mitotic rate also is increased during exposure to an irritant. This increase may, in part, reflect the repair of ulcerative damage seen in the first weeks after exposure to sulphur dioxide (Lamb and Reid, 1968), but cell division does not always seem proportional to such damage. For example, in one series of experiments, though two types of tobacco produced a similar increase in goblet cells flue-cured tobacco produced many more mitoses than air-cured tobacco (Lamb and Reid, 1969). In rats these changes have not been seen to develop into bronchial cancer, but a high mitotic count offers evidence of disturbance of cell division and presents features of bronchial damage additional to the increase in goblet cells. Detailed mitotic counts after exposure to tobacco smoke (Lamb and Reid, 1969) were not given in the previous report and so are reported here for the first time. Furthermore the higher mitotic count after exposure to flue-cured or barn-cured tobacco rather than to air-cured or Burley tobacco accords with the higher prevalence of human bronchial cancer after exposure to the

Department of Experimental Pathology, Institute of Diseases of the Chest, Brompton Hospital, London S.W.3

ROSEMARY JONES, F.I.M.L.T., Technician

ROSEMARY JONES, F.I.M.L.T., T

LYNNE REID, M.D., F.R.C.PATH., Professor former type of tobacco (Passey, Blackmore, Warbrick-Smith, and Jones, 1971).

Because of the relevance to human disease of the changes produced experimentally by tobacco smoke-increase in goblet cells and cells in mitosis-each count offers a suitable test for screening tobacco substitutes or additives.

Dalhamn (1966) and Dalhamn and Rylander (1971) have shown that phenylmethyloxadiazole (PMO), a substance first used as an antitussive agent, offers protection against the ciliostatic effect of tobacco smoke. At their suggestion we undertook the experiments reported here to test the effect of this additive on the increase in goblet cells and on the nature of the distribution of acid glycoprotein they contain, on the cells in mitosis, and on the epithelial thickness. The histochemical study of the intracellular mucus is reported separately (Jones, Bolduc, and Reid, 1972).

\section{Material and Methods}

The effect of two types of cigarette was investigated. Each was made with the same tobacco, but to the tobacco for one type $2 \%$ by weight of PMO was added.

In the experiments described here 41 Sprague-Dawley rats (Carworth Europe, CFY strain) from specific pathogen-free stock were used. The animals weighed about $150 \mathrm{~g}$ at the start of the experiment. Lungs from additional animals of the same batch were examined microscopically to ensure that lymphocytic infiltration was minimal (Reid, 1970).

The rats were divided into three groups-(1) tobacco, 15 animals exposed to cigarette without any additive; (2) tobacco and PMO, 15 animals exposed to cigarettes to which the anti-inflammatory agent PMO had been added; and (3) control, (a) 6 rats given a "sham" exposure in that they spent time in an exposure chamber as groups 1 and 2 but were subjected only to airflow and not to added tobacco smoke, and (b) 5 animals kept in cages. Since statistical analysis showed that groups $3 a$ and $3 b$ were indistinguishable for any of the features studied here, in this paper the results are presented with groups $3 a$ and $3 b$ added as the control group.

Groups 1 and 2 were exposed to 25 cigarettes a day. The animals were placed in an aluminium chamber and the cigarettes were burnt in a Wright Autosmoker (Wright, 1972). The details of exposure are similar to those reported by Lamb and Reid (1969). The animals were exposed four days a week for six weeks. The mean values of humidity and temperature for each chamber used for tobacco exposure were similar. The difference between the cages used for tobacco and sham exposures was greatest with respect to humidity, doubtless due in part to increased water loss from the animals induced either by the greater rise in temperature or by a nicotine effect, and perhaps because of the water vapour in the tobacco smoke. It has been shown that neither extremes of temberature nor humidity influence the number of goblet cells (Jones. Baetjer, and Reid, 1971).

During the four and a half hours or so of exposure no animal received food or water and the control animals were removed from the room. Apart from this period all animals spent their time in the same type of cage, in the same room, and with as much food and drink as required. Each day the chambers and the Autosmoker were cleaned.

The two types of cigarette supplied to us were identified by a code number whose key was not known to any one of us; it was not broken until it had been decided which cigarette had most effect on the animals.

The animals on whom the mitotic studies were to be made were left quietly in the same room for 18 hours before they were 
killed. Injection of colchicine $(0 \cdot 1 \mathrm{mg} / 100 \mathrm{~g}$ body weight), always at the same time of day, was given four hours before the animal was killed.

All animals were killed by intraperitoneal injection of $1-1.5 \mathrm{ml}$ of pentobarbitone sodium. Six of the animals were used for electron microscopical studies, two from each of groups 1 and 2 and one from each of groups $3 a$ and $3 b$. The results of the studies are reported elsewhere. The trachea, main bronchi, and lungs from all the animals were removed en bloc after being inflated with fixative through a tracheal injection until the pleura was tense. The lungs from the animals used for goblet cell counts (nine animals from each exposure group and six controls) were inflated with formol saline, and those from the animals injected with colchicine (four animals from each exposure group and three controls) for mitotic counts were inflated with Heidenhain Susa's solution. Lung sections were cut to include the full length of the main intrapulmonary bronchus and several of its side branches.

For goblet cell counts sections were stained with alcian blue at pH 2.6 and periodic-acid Schiff. Goblet cells were counted under oil immersion (field size $0.18 \mathrm{~mm}$ ) at three airway levels (a) along the full length of the trachea, $(b)$ along the medial wall of the axial pathway, and $(c)$ in 20 fields each of the second and third lateral airways. By the alcian blue and periodic-acid Schiff technique goblet cells may stain blue or red or as a mixture of these two colours.

Sections for mitotic counts were stained with haematoxylin and eosin. Cells in mitosis were counted along the same levels of the airway as for goblet cell studies, save that the trachea was considered at upper, middle and lower levels. A section of oesophagus at the mid-tracheal level was included.

\section{Results}

During the first eight exposures it was clear that as judged by their general condition of exhaustion one group of animals was affected more than the other. Within a few minutes of removal from the cabinet the animals that we subsequently designated group 2 recovered quickly and started cleaning themselves and moving about; the group 1 animals took about a quarter of an hour before starting this activity. This assessment was made in ignorance of the type of tobacco used, and it emerged only later that the less affected animals were receiving PMO. After further exposures the difference was no longer apparent. The mild conjunctivitis seen during the first days of exposure to tobacco smoke was similar in both groups.

\section{WEIGHT GAIN}

The pattern of weight gain for each animal group is illustrated in the Chart. There was no significant difference in this respect between the two tobacco groups but a significant difference was

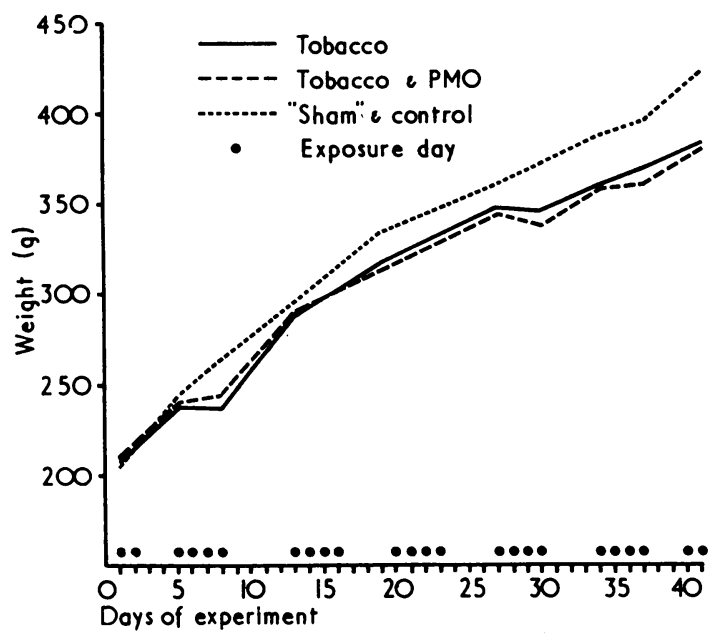

Weight gain related to exposure to either tobacco or tobacco and PMO. seen between these and the control animals $(P<0.001)$. The animals exposed to tobacco smoke failed to gain weight on the days of exposure; in the days between they gained weight faster and, at least in the first couple of weeks, their weight virtually regained the normal value.

\section{GOBLET CELL COUNT}

In the trachea the goblet cell count in the group of animals exposed to tobacco alone was significantly above that found either in the group exposed to tobacco and PMO $(P<0.001)$ or in the control animals $(P<0.01)$ (Table $I)$; there was no significant difference between the control animals and those exposed to tobacco and PMO. In the axial and lateral pathways in the animals exposed to tobacco goblet cells were increased, the increase being greater centrally than distally, although there was no significant difference between any of the groups.

TABLE I-Mean Goblet Cell Count (S.E. of Mean) per $6 \mathrm{~mm}$ of Airway Epithelium in Animals Exposed to Tobacco Alone (Group I) or Tobacco and PMO (Group 2)

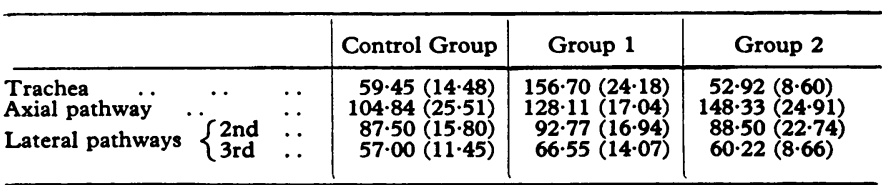

\section{EPITHELIAL THICKNESS AND CELL NUMBER}

In the upper trachea the epithelial thickness was measured with an eyepiece graticule as the vertical distance between the superficial surface of the basement membrane and the epithelial surface. Ten measurements were made over the plates of cartilage and 10 between, and the mean for each site was analyzed both for each animal and for each group. These were assessed separately because of an apparent increase between the plates, but no difference in any group was found between the values for the two sites (Table II).

TABLE II-Epithelial Thickness ( $\mu m)$ and Cell Number in the Upper Trachea (S.E. of Mean given in Parentheses)

\begin{tabular}{l|l|l|l|l}
\hline \multirow{2}{*}{} & \multicolumn{2}{|c|}{ Epithelial Thickness } & \multicolumn{2}{c}{ Cell Number } \\
\cline { 2 - 5 } & \multicolumn{1}{|c|}{ Over } & Between & \multicolumn{1}{c}{ Over } & \multicolumn{1}{c}{ Between } \\
\hline Control group & $12.18(0.66)$ & $14.35(1.64)$ & $2.30(0)$ & $2.70(0.17)$ \\
Group 1 & $21.37(0.67) *$ & $21.17(0.57) \dagger$ & $3.47(0.07) *$ & $3.40(0.10) 8$ \\
Group 2 & $15.68(0.90) \ddagger \|$ & $18.41(0.79) 8 \pi$ & $2.9(0.19) \pm \pi$ & $3.16(0.18) 8^{* *}$ \\
\hline
\end{tabular}

Over $=$ Measurements made over cartilage plates. Between $=$ Measurements made between cartilage plates.

$P<0.001$ against controls. P $<0.01$ against controls. $\mathbf{P}$
$\mathbf{N}$.S. against controls. ** N.S. against group 1 .

Heidenhain-Susa's solution being a better cytological fixative than formalin, the measurements of epithelial thickness and cell number were made on material fixed with this solution. Evidence of an increase in cell number contributing to the increase in thickness of the surface epithelium was sought by counting the number of nuclei transected by the vertical line along which the thickness measurement was made. In each tobacco group there was a highly significant increase in thickness compared with the controls, and this was greatest in group 1 . The difference between group 1 and group 2 was also highly significant. The results from the animals whose lungs had been fixed in formalin were always similar, although the degree of significance was not as high. The number of cells was also increased in groups 1 and 2 compared with the controls, although only the counts obtained over the cartilage plates achieved significance. 


\section{CELLS IN MITOSIS}

The number of cells in mitosis for the three groups of animals is given in Table III. At each of the three tracheal levels in groups 1 and 2 the number of cells in mitosis was found to be increased when compared with that of the controls, but the

TABLE III-Mitotic Count per 1,000 Cells for the Three Animal Groups

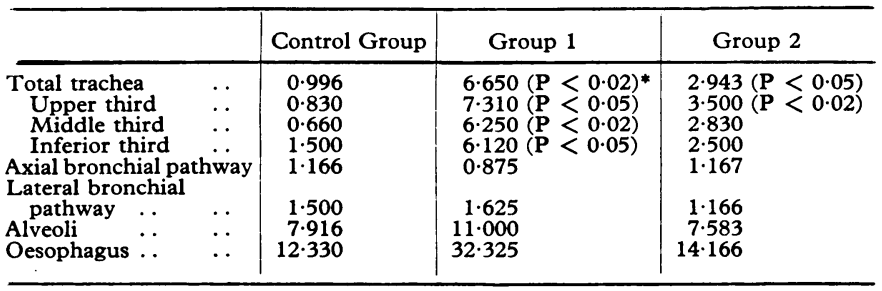

* Value of $\mathbf{P}$ given only where count in exposed animals was significant when compared with control animals.

increase in group 1 was higher than that in group 2. At each level the mitotic count was lower in group 2 than in group 1 , but at no single level did this achieve significance. When all values were taken in combination PMO had caused a significant reduction in cell division.

In the alveolar region group 2 was not different from the controls but the mitotic number in group 1 was higher, although not significantly so. The oesophageal count showed a progressive increase from the controls to group 2 to group 1, but these differences were also not significant.

It seems that tobacco alone led to failure to gain weight and to an increase in goblet cells, cells in mitosis, and epithelial thickness. PMO gave complete protection against the increase in goblet cells, partial protection against the increase in both number of cells in mitosis and epithelial thickness, and had no effect on the slower weight gain.

\section{Discussion}

For the first time an effective means of protection has been found against some of the changes produced in bronchial epithelium by tobacco smoke. In this, the first detailed quantification of mitotic numbers in rat lung after the application of tobacco smoke, the increase of cells in mitosis was found in large airways-the trachea and main bronchi-and not in the intrapulmonary airways. In the alveolar region there was no significant difference between any of the groups investigated, although the animals exposed to tobacco alone showed some increase in cells in mitosis. With light microscopy it is possible to identify dividing epithelial cells in the airways; electron microscopy is necessary to identify cells in the alveolar wall.

In the airways after exposure to sulphur dioxide it has been shown (Lamb and Reid, 1968) that in the first two days epithelial ulceration was much more severe than later and that the associated healing led to a great increase in cells in division. Preliminary analysis of the number of cells in mitosis after short-term exposure to tobacco smoke has shown a similar effect (P. Bolduc, unpublished observations). Since healing is usually complete within 14 days (Wilhelm, 1953) and the experiment described here was of six weeks' duration the early acute damage is unlikely to have been the cause of the increase. In the larger airways during later weeks of exposure to sulphur dioxide the mitotic count was somewhat raised, suggesting some continuing damage. It may be that such a situation occurs also after exposure to tobacco smoke, but it is likely that there is, in addition, some effect on mitosis peculiar to tobacco smoke. This is suggested by the striking difference in the number of cells in mitosis arising from exposure to different types of tobacco although goblet cell increase was similar (Lamb and Reid, 1968).

A variety of irritants have been shown to produce an increase in goblet cells. This increase is seen in epithelium where the mitotic count is not necessarily raised. It is also induced by the parenteral administration of isoprenaline and pilocarpine (Sturgess, 1970; Sturgess and Reid, 1972)-that is, experimentally induced by irritation or as a result of a pharmacological effect. Histochemical analysis (Jones et al., 1972) has shown that in addition to the increase in goblet cells tobacco produces a change in the distribution of acid glycoprotein throughout the goblet cell population.

The failure of animals exposed to tobacco smoke to gain weight was investigated by Elson and Passey (1963). They found a similar effect from nicotine even without tobacco smoke.

Not all these changes resulting from the effect of tobacco smoke were modified by PMO to the same extent, confirming that various mechanisms are concerned in their production, either singly or in combination. While PMO does not prevent the metabolic-mediated or nicotine-mediated effect it completely prevented an increase in goblet cells. If there is a single cause of mitotic increase it may be modified by PMO; if, as seems likely, at least two factors are operating, one peculiar to tobacco smoke, the other non-specific, then it may be that only one is susceptible. In view of the suppression of goblet cell increase it may be that it is the non-specific effect which is susceptible. But until the effect of PMO on the epithelial response to other irritants has been followed this is not certain.

The preliminary results of the histochemical studies indicate that the effect of PMO does not prevent all effects of tobacco smoke on goblet cells. For example, the intracellular shift in type of acid glycoprotein occurs although goblet cell increase is suppressed. This is being analysed further, as is the effect of PMO on the changes produced by tobacco smoke in the early stage of exposure.

In the airways the influence of PMO on the ciliostatic effect of tobacco smoke has been investigated by administering PMO mixed with the tobacco in the cigarette (Dalhamn and Rylander, 1971) and also by oral administration of oxolamine citrate, the parent compound of PMO (Dalhamn, 1966). By both routes a protective effect was shown, suggesting that these compounds modify the tissue not the tobacco smoke.

This substance justifies further study as a possible additive to tobacco, but whether or not it ultimately proves of value for this purpose it does permit a more effective analysis of the damage done to airway epithelium by tobacco smoke.

We are grateful to Professor Bernard Benjamin for advice with the statistical analysis, and to the Lorillard Company, who provided the cigarettes. Professor T. Symington and the late Professor R. Passey kindly allowed us to use the smoking machines in Chester Beatty Research Institute. This work was supported by grants from the Medical Research Council and the Karolinska Institute, Stockholm.

\section{References}

Dalhamn, T. (1966). American Review of Respiratory Diseases, 94, 799.

Dalhamn, T., and Rylander, R. (1971). Report from the Institutes of Hygiene Upsala University and Karolinska Institute, and the Department of Environmental Hygiene, National Institute of Public Health, Stockholm, Sweden.

Elson, L. A., and Passey, R. D. (1963). Acta; Unio Internationalis Contra Cancrum, 19, 715.

Freeman, G., and Haydon, G. B. (1964). Archives of Environmental Health,

Jones, R., Baetjer, A., and Reid, L. (1971). British fournal of Industrial Medicine, 28, 369.

Jones, R., Bolduc, P., and Reid, L. (1972). In preparation.

Jones, R., Bolduc, P., and Reid, L. (1972). In preparation. Lamb, D., and Reid, L. (1968). Fournal of Pathology and Bacterio

Lamb, D., and Reid, L. (1969). British Medical Fournal, 1, 33. awdesley-Thomas, L., Healey, P., and Barry, D. (1971). In Proceedings of an International Symposium on Inhaled Particles, ed. W. H. Walton, vol. 1, p. 509. London, Unwin Bros.

Passey, R. D., Blackmore, M., Warbrick-Smith, D., and Jones, R. (1971). British Medical Fournal, 4, 198.

Reid, L. (1970). Archives of Internal Medicine, 126, 428.

Sturgess, J. (1970). The Control of the Bronchial Mucous Glands and their Secretion. Ph.D. London University.

Sturgess, J., and Reid, L. (1972). In preparation.

Wilhelm, D. L. (1953). Fournal of Pathology and Bacteriology, 65, 543.

Wright, M. (1972). Submitted for publication. 